\title{
A model of magnesium metabolism in young sheep: transactions between plasma, cerebrospinal fluid and bone
}

\author{
A. B. Robson ${ }^{1}$ †, A. R. Sykes ${ }^{2}$, A. E. McKinnon ${ }^{1 *}$ and S. T. Bell ${ }^{2}$ \\ ${ }^{1}$ Applied Computing, Mathematics and Statistics Group, Applied Management and Computing Division \\ ${ }^{2}$ Animal and Veterinary Sciences Group, Animal and Food Sciences Division, Lincoln University, Canterbury, \\ New Zealand
}

(Received 14 July 2003 - Accepted 28 August 2003)

\begin{abstract}
An extension of the previously proposed model of Mg metabolism (Robson et al. 1997) has been developed to consider the transactions of $\mathrm{Mg}$ that are associated with cerebrospinal fluid (CSF) and bone. The representation of the CSF as a single Mg compartment with uptake from the plasma described by Michaelis-Menten kinetics gives very good agreement with published experiments. Analysis of the available information on resorption of $\mathrm{Mg}$ from adult bone indicates that this process makes a negligible contribution to $\mathrm{Mg}$ homeostasis and can be omitted from the model.
\end{abstract}

Magnesium: Mathematical modelling: Hypomagnesaemia: Grass tetany: Simulation

Hypomagnesaemic tetany occurs in ruminant animals when the $\mathrm{Mg}$ concentration of the cerebrospinal fluid (CSF) falls below approximately $0.66 \mathrm{mmol} / \mathrm{l}$ (Meyer \& Scholz, 1972). Normally the concentration of $\mathrm{Mg}$ in CSF is higher than that of plasma (Meyer \& Scholz, 1972; Beal \& Bligh, 1977). Bito (1969) and Oppelt et al. (1963) have demonstrated that an active transport mechanism is involved in transporting $\mathrm{Mg}$ from blood to CSF, and Oppelt et al. (1963) further showed that diffusion and bulk filtration are responsible for the removal (of $\mathrm{Mg}$ ) from the CSF.

Pauli \& Allsop (1974) found that the onset of hypomagnesaemic tetany in two groups of four dairy cows, both grazing spring pasture, was more closely associated with low CSF $\mathrm{Mg}$ levels than with low plasma Mg levels. In the affected animals (group A) the CSF levels were $0.52 \mathrm{mmol} \mathrm{Mg} / \mathrm{l}$ with plasma levels of $0.22 \mathrm{mmol} \mathrm{Mg} / \mathrm{l}$, whereas the unaffected animals (group B) had CSF and plasma levels of 0.77 and $0.16 \mathrm{mmol} \mathrm{Mg} / \mathrm{l}$ respectively. Allsop \& Pauli (1975a) showed that the CSF concentration in grazing dairy cows was significantly lower in clinically affected $(0.51 \mathrm{mmol} \mathrm{Mg} / \mathrm{l})$ than in non-tetanic animals $(0.73 \mathrm{mmol} /$ 1), despite the plasma $\mathrm{Mg}$ concentrations being similar (0.20 mmol Mg/l v. $0.15 \mathrm{mmol} \mathrm{Mg/l} \mathrm{respectively).}$

In a later experiment in sheep, Allsop \& Pauli (1975b) were able to induce episodes of tetany by perfusion of the ventriculolumbar space with synthetic CSF containing $<0.25 \mathrm{mmol} \mathrm{Mg} / \mathrm{l}$, and could abolish these tetanic episodes by perfusion with fluid of normal $\mathrm{Mg}$ concentration $(1.00 \mathrm{mmol} / \mathrm{l})$.
From these field and experimental observations, it is apparent that the clinical symptoms of hypomagnesaemic tetany are caused by a reduction in the CSF Mg concentration and it is thus important to understand the processes that contribute to low CSF Mg levels.

Bone has a Ca:Mg ratio of about 50:1 (Sykes \& Russel, 2000) and so is a potential source of $\mathrm{Mg}$ for contributing to whole-animal $\mathrm{Mg}$ homeostasis, particularly in young animals. Field (1960) estimated the quantity of $\mathrm{Mg}$ available from bone in sheep to be $160-200 \mathrm{mg}$. This is equivalent to the estimated endogenous faecal loss for $1 \mathrm{~d}$ for an animal of $60 \mathrm{~kg}$ body weight (Agricultural Research Council, 1980). In cattle, Storry \& Rook (1963) estimated the $\mathrm{Mg}$ available from bone to be about $0.5 \mathrm{~g} / \mathrm{d}$, which is small in comparison to the $2.4 \mathrm{~g} \mathrm{Mg}$ required per $\mathrm{d}$ for the production of 20 litres milk.

The present paper reviews the mechanisms describing the inflow and outflow of $\mathrm{Mg}$ between plasma and CSF and develops a mechanistic description of them for inclusion in our earlier model of $\mathrm{Mg}$ metabolism in sheep (Robson et al. 1997). We also investigate the possible contribution that the $\mathrm{Mg}$ reservoirs in bone could make to $\mathrm{Mg}$ homoeostasis.

\section{Methodology \\ Relationship between plasma and cerebrospinal fluid magnesium}

The relationship between the concentration of $\mathrm{Mg}$ in the $\mathrm{CSF}(y, \mathrm{mg} / 100 \mathrm{ml})$ and the $\mathrm{Mg}$ concentration in plasma

\footnotetext{
Abbreviation: CSF, cerebrospinal fluid.

* Corresponding author: Dr Alan E. McKinnon, fax +64 3 3253839, email mckinnon@lincoln.ac.nz

$\dagger$ Deceased.
} 
$(x, \mathrm{mg} / 100 \mathrm{ml})$ in sheep offered a low-Mg $(0 \cdot 14 \mathrm{~g} / \mathrm{kg})$ diet (Meyer \& Scholz, 1972) was given by:

$$
y=2 \cdot 41-\frac{0 \cdot 261}{x} .
$$

No effects of age, sex or lactational status were observed.

Following the successful elevation of CSF Mg levels by rectal infusion of $\mathrm{Mg}$ (Meyer \& Busse 1975a), the influence of hypermagnesaemia on the concentration of $\mathrm{Mg}$ in the CSF was investigated by Meyer \& Busse (1975b). An intravenous bolus of magnesium gluconate elevated plasma $\mathrm{Mg}$ concentration from 0.75 to $4.00 \mathrm{mmol} / \mathrm{l}$ within $5 \mathrm{~min}$ and this remained $>1.3 \mathrm{mmol} / \mathrm{l}$ for the ensuing $120 \mathrm{~min}$. They reported an increase in the CSF $\mathrm{Mg}$ concentration in the lumbar region from 0.92 to $1.03 \mathrm{mmol} / \mathrm{l}$ in normal sheep. An increase in concentration of $\leq 0.17 \mathrm{mmol} / \mathrm{l}$ was observed in animals that had been offered a $\mathrm{Mg}$-deficient diet and had a low CSF Mg concentration before the treatment. In both cases, the increase in concentration of $\mathrm{Mg}$ in the CSF occurred at different times and was of variable duration in each of the cerebral ventricles, and in the cisterna magna and lumbar regions of the cerebrospinal column.

Cox (1977) investigated the effects of hypermagnesaemia on the concentration of $\mathrm{Mg}$ in the CSF in dairy cows. The concentration of $\mathrm{Mg}$ in the CSF increased by $10-15 \%$ as a result of sevenfold elevations in serum $\mathrm{Mg}$ concentration. These observations are consistent with those of Meyer \& Busse $(1975 b)$ and those of Meyer \& Scholz (1972), in that a saturable process was observed to operate for the transport of $\mathrm{Mg}$ between plasma and the CSF.

\section{Model of magnesium in the cerebrospinal fluid}

Robson et al. (1997) described a model of Mg metabolism in sheep. The experimental observations outlined earlier were used to extend this model to include a compartment associated with CSF. To do this, it was necessary to develop relationships that describe the volume, production and clearance rates of CSF. The notation used follows Tables 1 and 2 of Robson et al. (1997).

The rate of change of $\mathrm{Mg}$ in the CSF is given by the mass balance equation:

$$
\frac{d Q_{C s}}{d t}=U_{P l C s}-U_{C s P l}
$$

where $Q_{C s}$ is the amount of $\mathrm{Mg}$ in the CSF, $U_{P l C s}$ is the rate of flow of $\mathrm{Mg}$ from plasma to the CSF and $U_{C s P l}$ is the rate of flow of $\mathrm{Mg}$ from the CSF to plasma.

The detailed expressions and parameters for $U_{P I C s}$ and $U_{C s P l}$ are derived in the following sections.

\section{Cerebrospinal fluid volume}

The relationship between brain mass $\left(M_{B}, \mathrm{~g}\right)$ and body weight $(W, \mathrm{~kg})$ has been established for many mammals by Brody (1945) as:

$$
M_{B}=9.96 W^{0.697} \text {. }
$$

Other workers (see Peters, 1983, Appendix IVe) have found similar allometric relationships. Given that the specific gravity of brain tissue is 1.040 (Cserr, 1971), brain volume can be readily estimated.

The brain volume of Jersey cows was measured by Cox (1977), who found that animals with a mean body weight of $318 \mathrm{~kg}$ had a brain volume of $445 \mathrm{ml}$. This compares well with a value of $531 \mathrm{ml}$ computed using equation 3 . Cox (1977) also obtained the average CSF volume by two different experimental methods and reported a value of $186 \mathrm{ml}$ as the average of the two methods. Consequently, CSF volume $\left(V_{C s}\right)$ was estimated as $42 \%$ of the brain volume and is given by:

$$
V_{C S}(\mathrm{ml})=0.42 \times \frac{9.96}{1.04} W^{0.697}=4.02 W^{0.697} .
$$

\section{Cerebrospinal fluid production and clearance rates}

Cserr (1971) gives the CSF production rate across many mammalian species as $0.5 \% \mathrm{CSF}$ volume per min. This can be expressed as $7 \cdot 2 V_{C s}$ per $\mathrm{d}$. CSF is produced mainly by the choroid plexus and is cleared back into the blood by bulk flow through the arachnoid villi.

The CSF volume as computed earlier $(212 \mathrm{ml}$ for a $320 \mathrm{~kg}$ animal) is small compared with the plasma volume estimated at 19.2 litres by Cox (1977) using a value of $60 \mathrm{ml}$ plasma $/ \mathrm{kg}$ body weight (Panaretto, 1964). Therefore, the effect of clearance of $\mathrm{Mg}$ from the CSF on the plasma $\mathrm{Mg}$ concentration will be negligible. Since the combined volume of brain and CSF system is contained in the fixed volume of the skull and spinal column, it is assumed that the CSF clearance rate is equal to the CSF production rate.

\section{Magnesium uptake and clearance in the cerebrospinal fluid}

The rate of flow of $\mathrm{Mg}(\mathrm{mol} / \mathrm{d})$ from the CSF to the plasma is given by the product of the CSF clearance rate and the concentration of $\mathrm{Mg}$ in that secretion. Therefore:

$$
U_{C s P l}=7 \cdot 2 V_{C s} C_{C s}
$$

Using

$$
C_{C s}=\frac{Q_{C s}}{V_{C s}}
$$

we can write:

$$
U_{C s P l}=r_{M g C s P l} Q_{C s},
$$

where $r_{M g C s P l}=7 \cdot 2 / \mathrm{d}$.

Transport of solutes across the choroid plexus requires energy and is sensitive to the effects of dinitrophenol and ouabain (Cserr, 1971). This energy dependency and the transport rate temperature sensitivity (Davson, 1967) are the hallmarks of an active transport process commonly represented by Michaelis-Menten kinetics (Martens et al. 1978). The saturation relationship in equation 1 is consistent with such a process. Michaelis-Menten kinetics describe the rate of change $(v)$ of a substance in or from a system in terms of the active concentration $(x)$ of that 
substance in the system such that:

$$
v=\frac{V_{\max }}{1+\frac{K_{\mathrm{m}}}{x}} .
$$

By plotting $v: x$ as abscissa against $v$ as ordinate (the Eadie-Hofstee plot), $K_{\mathrm{m}}$ and $V_{\max }$ can readily be obtained (Martens, 1983). In our case, $x$ corresponds to the concentration of $\mathrm{Mg}$ in plasma $\left(C_{P l}\right)$ and $v$ corresponds to the rate of flow of $\mathrm{Mg}$ from plasma to the CSF per unit volume of CSF, so that:

$$
U_{P l C s}=v V_{C s}=\frac{V_{\max } V_{C s}}{1+\frac{K_{\mathrm{m}}}{C_{P l}}} .
$$

The $V_{C s}$ term in equation 9 scales the flow rate of $\mathrm{Mg}$ between plasma and the CSF according to the volume of the CSF.

If we assume that the results reported by Meyer \& Scholz (1972) were for animals whose CSF Mg concentrations were at steady state, we can set equation 2 to zero so that:

$$
U_{P l C s}=\frac{V_{\mathrm{max}} V_{C s}}{1+\frac{K_{\mathrm{m}}}{C_{P l}}}=r_{M g C s P l} C_{C s} V_{C s} .
$$

Using the values from Meyer \& Scholz (1972, Table 3) (i.e. measured values for $C_{P l}$ and $C_{C s}$ ) we created an Eadie-Hofstee plot (Martens, 1983) based on equation 10 and obtained estimates for $V_{\max }$ and $K_{\mathrm{m}}$ of 7.890 and $0 \cdot 112 \mathrm{mmol} \mathrm{Mg} / \mathrm{l}$ respectively.

\section{Testing the model of cerebrospinal magnesium}

Our plan was to extend the model defined in Robson et al. (1997) by the addition of equations 2, 4, 7 and 9 with the necessary alterations to the plasma mass-balance equation being made. Here, we intended to first test equations 2, 7 and 9 to determine if they were a reasonable representation of the $\mathrm{Mg}$ dynamics between plasma and CSF.

Both Allsop \& Pauli (1985) and Meyer \& Scholz (1972) have reported experiments in which the time course of plasma and CSF Mg concentrations were measured in animals on various dietary $\mathrm{Mg}$ regimens. Allsop \& Pauli (1985) carried out their experiment on six lactating Friesian cows that were fed a low-Mg diet for $16 \mathrm{~d}$. Two of these animals were given an intravenous infusion of $\mathrm{Mg}$ after being on the $\mathrm{Mg}$-deficient diet for $10 \mathrm{~d}$. Meyer \& Scholz (1972) carried out their experiment on sheep that were also fed a low-Mg diet. Both experiments were simulated using the model developed as described earlier. The measured plasma $\mathrm{Mg}$ concentrations were used as the values of $C_{P l}$. These were linearly interpolated where necessary. The initial values of both $C_{P l}$ and $C_{C s}$ used in the simulations were taken as the time zero values reported by the authors.

As we are working with concentrations of $\mathrm{Mg}$ in plasma and in the CSF and if we assume that the volume of the $\operatorname{CSF}\left(V_{C s}\right)$ is constant, we can rewrite equation 2 with concentration as the state variable as follows:

$$
\frac{d C_{C s}}{d t}=\frac{V_{\max }}{1+\frac{K_{\mathrm{m}}}{C_{P l}}}-r_{M g C s P l} C_{C s} .
$$

This is independent of CSF volume $\left(V_{C s}\right)$.

For the Meyer \& Scholz (1972) experiment, the values of both plasma and CSF Mg concentrations were taken from the 'Young animals' column of their Table 3, which shows the mean values of measurements taken from a number of animals as a function of the 'Depletion time'. Where the depletion time is given as a range of days, the midpoint of the range was used as the time value.

To simulate the procedure reported by Allsop \& Pauli (1985) in which the plasma and CSF Mg concentrations were measured for $16 \mathrm{~d}$ following the introduction of a depletion diet, the values of plasma and CSF Mg concentrations were taken from their Fig. 1. To simulate the procedure where $10 \mathrm{~d}$ on a depletion diet was followed by an intravenous infusion of $\mathrm{Mg}$, the plasma and CSF $\mathrm{Mg}$ values were taken from their Fig. 2. We compare our CSF results with their measurements from the ventricular region.

\section{Rate of magnesium removal from bone}

The skeleton contains approximately $80 \%$ of whole-body $\mathrm{Mg}$ (Larvor, 1983). Because there is no known mechanism for direct resorption of $\mathrm{Mg}$ from bone, this potential reservoir will not contribute significant amounts of $\mathrm{Mg}$ to assist with whole-animal $\mathrm{Mg}$ homeostasis unless the rate of $\mathrm{Ca}$ mobilization, and consequently the rate of $\mathrm{Mg}$ mobilization, is high. The rate at which $\mathrm{Ca}$ is mobilized from the skeleton is discussed in the following section.

\section{Role of magnesium in bone turnover}

Moate et al. (1980) studied the relationship between dietary $\mathrm{Ca}$ absorption in normal and hypomagnesaemic sheep in an attempt to ascertain whether or not $\mathrm{Ca}$ absorption in the gastrointestinal tract was affected by the level of $\mathrm{Mg}$ in plasma. Their hypothesis was that if hypomagnesaemia induced mobilization of $\mathrm{Ca}$, and consequently $\mathrm{Mg}$ from bone, then the $\mathrm{Ca}$ requirement of the animal would be lowered and this would be observed as a reduction in dietary $\mathrm{Ca}$ absorption. They were unable to observe a change in the percentage of administered ${ }^{47} \mathrm{Ca}$ that was absorbed between Mg-depleted sheep (plasma $\mathrm{Mg}$ concentration $0.38 \mathrm{mmol} / \mathrm{l}$ ) and control sheep (plasma $\mathrm{Mg}$ concentration $0.81 \mathrm{mmol} / \mathrm{l})$. They concluded that there was no effect on the gastrointestinal absorption of $\mathrm{Ca}$, and therefore change in bone turnover, as a consequence of $\mathrm{Mg}$ deficiency.

Contreras et al. (1982) investigated the effects of normomagnesaemia and hypomagnesaemia $(<0.85 \mathrm{mmol} / \mathrm{l})$ on the rate of $\mathrm{Ca}$ mobilization in cattle using an intravenous infusion of $\mathrm{Na}$ EDTA. Hypomagnesaemia reduced the rate of $\mathrm{Ca}$ chelation that these authors concluded reflected reduced mobilization from bone.

In a similar experiment, Terashima et al. (1988) examined the effects of diets known to influence the plasma $\mathrm{Mg}$ status of animals on the rate of $\mathrm{Ca}$ mobilization from 
bone of wether sheep. Four diets were used $(\mathrm{g} / \mathrm{kg})$ : control diet (Mg 2.3, K 7.6); low-Mg diet (Mg 0.4, K 7.5); control plus high-K diet (Mg 1.9, K 49.0); low Mg high-K diet (Mg 0.4, K 46.8). Plasma levels of $\mathrm{Mg}$ on these diets were $1.05,0.55,0.74$ and $0.61 \mathrm{mmol} / 1$ respectively. As in the experiments of Contreras et al. (1982) discussed earlier, Ca mobilization was determined by intravenous infusion of EDTA for $60 \mathrm{~min}$. The authors observed that 4.98, 3.83, 3.23 and $3.58 \mathrm{mmol} \mathrm{Ca}$ were mobilized during the infusion period. From these observations they concluded that hypomagnesaemic sheep may be susceptible to hypocalcaemia due to depressed ability for $\mathrm{Ca}$ mobilization. These findings are supported by endocrine studies that have shown low concentrations of parathyroid hormone in sheep (Shiga et al. 1980) and low responsiveness of the isolated perfused tibia of dogs to parathyroid hormone (Rude et al. 1978) in $\mathrm{Mg}$ deficiency.

Gardner (1973) found the rate of mobilization of $\mathrm{Mg}$ from body reserves of ewes subjected to peritoneal dialysis was $17-80 \mathrm{mg} \mathrm{Mg} / \mathrm{d}$. Haemodialysis with a Mg-free medium, however, produced mobilization rates of $20-30 \mathrm{mg} \mathrm{Mg} / \mathrm{h}$ (480-720 mg Mg/d), which was sufficient to maintain the plasma level of $\mathrm{Mg}$. When $\mathrm{Ca}$ was removed from an animal by dialysis with a Ca-free medium, there was a significant transfer of $\mathrm{Mg}$ from the animal to the dialysate. Conversely, when dialysis was performed with a $\mathrm{Mg}$-free medium, there was a significant transfer of $\mathrm{Ca}$ from the animal to the dialysis medium. From these results, Gardner (1973) concluded that the site of this $\mathrm{Mg}$ reservoir was bone.

Van de Braak et al. $(1986 a, b)$ established that only dairy cows offered a low-Ca intake in association with low total feed intake and adequate $\mathrm{Mg}$ intake tended to increase $\mathrm{Ca}$ mobilization from bone when infused with $\mathrm{Na}$ EDTA in the peripartum period. They further demonstrated (Van de Braak et al. 1987a,b) that the rate of Ca mobilization from bone induced by Na EDTA infusion was reduced by a low dietary $\mathrm{Mg}$ intake. A further complication, if the rate of $\mathrm{Mg}$ release from the skeleton is dependent on bone turnover, is their observation (Van de Braak et al. 1987a) that bone $\mathrm{Ca}$ resorption makes only a minor contribution to the total Ca supply at parturition in older cows.

The work reported here investigates the level of plasma $\mathrm{Mg}$ at which Ca resorption is affected and whether or not it is possible to consider bone turnover as giving access to a reservoir which may be utilized by the animal for $\mathrm{Mg}$ homeostasis.

\section{Results and discussion}

\section{Model of magnesium in the cerebrospinal fluid}

The simulation results of the Meyer \& Scholz (1972) experiment and the two procedures from Allsop \& Pauli (1985) are shown in Fig. 1 and Figs. 2 and 3 respectively. Given that there has been no adjustment of model parameters, the agreement between the observed and simulated CSF $\mathrm{Mg}$ concentrations is very satisfactory. It is important to note that, because equation 11 is independent of CSF volume, these results do not provide verification of equation 4, which estimates CSF volume from animal body weight.

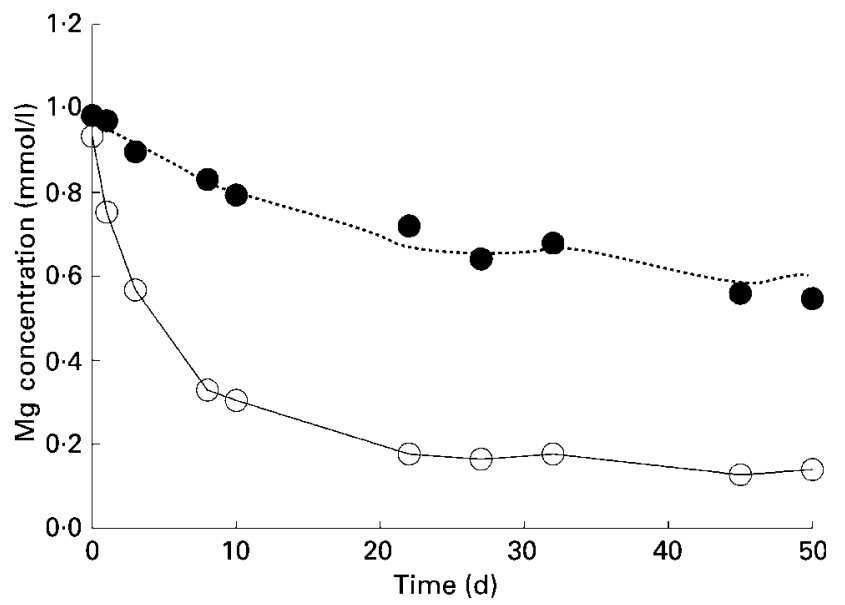

Fig. 1. Simulation of the experiment reported by Meyer \& Scholz (1972): plasma and cerebrospinal fluid magnesium concentrations were measured in sheep on a magnesium-deficient diet. The plasma magnesium concentrations were linearly interpolated. $\mathrm{O}$, Measured plasma magnesium concentration; ...., simulated cerebrospinal fluid magnesium concentration; •, measured cerebrospinal fluid magnesium concentration.

The clearance rate of $\mathrm{Mg}$ from the CSF in the model $\left(r_{M g C s P l}\right)$ is dependent only on the CSF flow rate. The flow rates of CSF reported by several workers are remarkably consistent. Cserr (1971) gives 0.5\% CSF volume per min, which gives the fractional daily clearance rate of $7 \cdot 2$ used earlier. Feldman (1989, p. 837) cites a value for man of 6-7 times per d, and he further notes (p. 839) a value of $290 \mu \mathrm{l} / \mathrm{min}$ in a calf. This gives a fractional daily turnover rate of 4.4 assuming a $100 \mathrm{~kg}$ animal has a CSF volume of $94 \mathrm{ml}$ (calculated using equation 4). Allsop (1986) observed in vitro a flow of approximately $210 \mu \mathrm{l} / \mathrm{min}$, which on the same basis gives a turnover rate of 6.6/d.

Given the observation of Allsop \& Pauli (1985) of a significant difference between the lumbar and ventricular CSF Mg concentrations, the model detailed here is

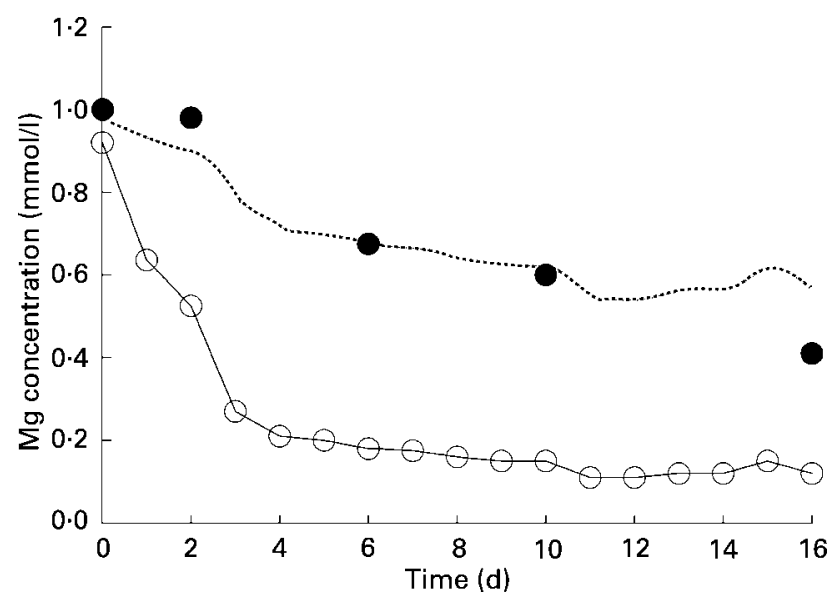

Fig. 2. Simulation of the procedure reported by Allsop \& Pauli (1985): plasma and cerebrospinal fluid magnesium concentrations were measured in cows on a magnesium-deficient diet. The plasma magnesium concentrations were linearly interpolated. $O$, Measured plasma magnesium concentration; ...., simulated cerebrospinal fluid magnesium concentration; $\bullet$, measured cerebrospinal fluid magnesium concentration. 


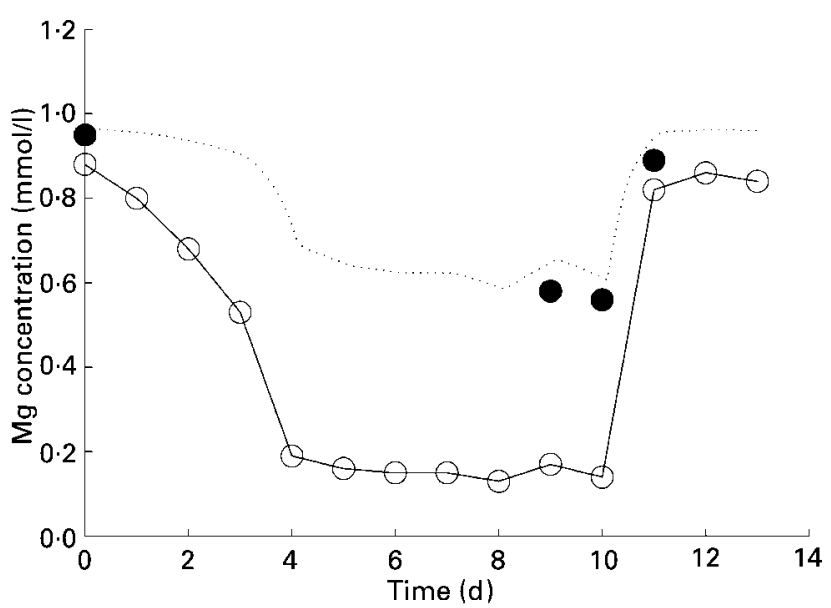

Fig. 3. Simulation of the procedure reported by Allsop \& Pauli (1985): plasma and cerebrospinal fluid magnesium concentrations were measured in two cows on a magnesium-deficient diet. After $10 \mathrm{~d}$ the animals were given an intravenous infusion of magnesium. The plasma magnesium concentrations were linearly interpolated. $\mathrm{O}$, Measured plasma magnesium concentration; ...., simulated cerebrospinal fluid magnesium concentration; $\bullet$, measured cerebrospinal fluid magnesium concentration.

deficient in that it considers the source of $\mathrm{Mg}$ to the cerebrospinal system to be only of choroid plexus origin. Cox (1977), however, states that he was unable to observe differences between the lumbar and ventricular CSF $\mathrm{Mg}$ concentrations, despite the fact that with ${ }^{28} \mathrm{Mg}$-labelled material he was able to observe a temporal difference in the arrival of radioactivity at these different sites in the CSF system. Allsop \& Pauli (1985) observed that when depleted cows were repleted with intravenous $\mathrm{Mg}$, the ventricular CSF $\mathrm{Mg}$ concentration was restored to normal levels within $24 \mathrm{~h}$, but it was a further $48-72 \mathrm{~h}$ before the lumbar CSF was restored to normal levels. This also suggests $\mathrm{Mg}$ transport down a diffusional concentration gradient in the cerebrospinal column or alternatively, a secondary source of $\mathrm{Mg}$ transport into the CSF operating in the lumbar region.

The transport of $\mathrm{Mg}$ across the rumen wall is affected by intra-ruminal K concentration (Martens \& Blume, 1986). Pauli \& Allsop (1974) observed an increase in plasma $\mathrm{K}$ concentration in animals suffering from grass tetany and it is possible that similar K-dependent transport mechanisms operate at the choroid plexus as occur at the rumen wall. CSF is known to be electrically slightly positive with respect to blood by a few $\mathrm{mV}$ (Bito, 1969; Cserr, 1971, p. 292), so the transchoroidal potential could be generated by the $\mathrm{K}$ gradient. An effect of elevated $\mathrm{K}$ levels on the transport of $\mathrm{Mg}$ across the choroid plexus has been observed by Parkinson \& Leaver (1980) in vivo in an anaesthetized sheep; mild hyperkalaemia (plasma $\mathrm{K}^{+}>5 \mathrm{mmol} / \mathrm{l}$ ) reduced, within minutes, the concentration of $\mathrm{CSF} \mathrm{Mg}$ from 0.93 to $0.85 \mathrm{mmol} / 1$ (Parkinson \& Leaver, 1980). There is support for this finding in the in vitro studies of Allsop (1986), in which choroid plexus Mg concentration decreased in response to an increase in $\mathrm{K}$ concentration in a perfusion medium introduced into the brain via an internal carotid artery.

It can be postulated that a possible mechanism for the onset of tetany is a stress reaction involving the adrenal-glucocorticoid axis, which increases plasma $\mathrm{K}^{+}$concentration and, by similar mechanisms as pertain at the rumen wall, triggers the lowering of $\mathrm{Mg}$ transport across the choroid plexus. There is direct evidence, for example, that aldosterone can effect a direct and immediate change in $\mathrm{Mg}$ metabolism in the rumen (Charlton \& Armstrong, 1989), and clinical experience certainly implicates stressful environmental conditions as trigger factors for clinical disease.

Hypocalcaemia has often been observed in association with clinical symptoms following prolonged hypomagnesaemia (Hemingway \& Ritchie, 1965; Allsop \& Pauli $1975 a, b)$. The findings of Allsop (1986), from in vivo studies of the isolated perfused choroid plexus of sheep, that the rate of transfer of $\mathrm{Mg}$ into choroid plexus fluid was not affected by decreasing Ca concentration in the perfusing fluid suggests that the hypocalcaemia is a consequence rather than a cause of hypomagnesaemia, as argued in the next section, and therefore no attempt was made to allow for it in the model.

\section{Magnesium-bone interactions}

Table 1 summarizes data from the literature and presents derived values for a mean Ca resorption rate $\left(\mathrm{R}^{\prime}\right)$ that has been corrected for differing metabolic live weights (live weight ${ }^{0.75}$ ). When the derived values for $\mathrm{R}^{\prime}$ are plotted

Table 1. Calcium resorption rate from bone $(\mathrm{R})$ as a function of plasma magnesium concentration (Mean values)

\begin{tabular}{|c|c|c|c|c|c|c|c|}
\hline $\mathrm{R}(\mathrm{mmol} / \mathrm{h})$ & $\mathrm{Mg}(\mathrm{mmol} / \mathrm{l})$ & $\mathrm{Ca}(\mathrm{mmol} / \mathrm{l})$ & W (kg) & $n$ & $w^{0.75}$ & $\mathrm{R}^{\prime}\left(\mathrm{mmol} / \mathrm{h}\right.$ per $\left.\mathrm{W}^{0.75}\right)$ & Reference \\
\hline \multicolumn{8}{|l|}{ Sheep } \\
\hline 4.98 & 1.05 & $2 \cdot 05$ & 45 & 4 & $17 \cdot 37$ & 0.286 & Terashima et al. (1988) \\
\hline 3.55 & 0.63 & $2 \cdot 16$ & 45 & 4 & $17 \cdot 37$ & 0.204 & Terashima et al. (1988) \\
\hline \multicolumn{8}{|l|}{ Steers } \\
\hline $19 \cdot 2$ & 0.9 & 2.59 & 258.5 & 6 & 64.47 & 0.298 & Contreras et al. (1982) \\
\hline $13 \cdot 1$ & 0.71 & 2.52 & 262.5 & 6 & $65 \cdot 21$ & 0.201 & Contreras et al. (1982) \\
\hline \multicolumn{8}{|l|}{ Cattle } \\
\hline $15 \cdot 9$ & 0.54 & $2 \cdot 3$ & $538 \cdot 2$ & 6 & $111 \cdot 74$ & 0.142 & Contreras et al. (1982) \\
\hline $24 \cdot 7$ & 1.00 & $2 \cdot 3$ & $528 \cdot 7$ & 6 & $110 \cdot 26$ & 0.224 & Contreras et al. (1982) \\
\hline $16 \cdot 2$ & 0.65 & 2.48 & $608 \cdot 8$ & 7 & $122 \cdot 56$ & 0.132 & Van de Braak et al. (1987b) \\
\hline $22 \cdot 2$ & $1 \cdot 16$ & 2.65 & $593 \cdot 1$ & 8 & $120 \cdot 18$ & 0.185 & Van de Braak et al. (1987b) \\
\hline
\end{tabular}

$\mathrm{W}$, live weight; $\mathrm{R}^{\prime}$, calcium resorption rate corrected for metabolic live weight. 


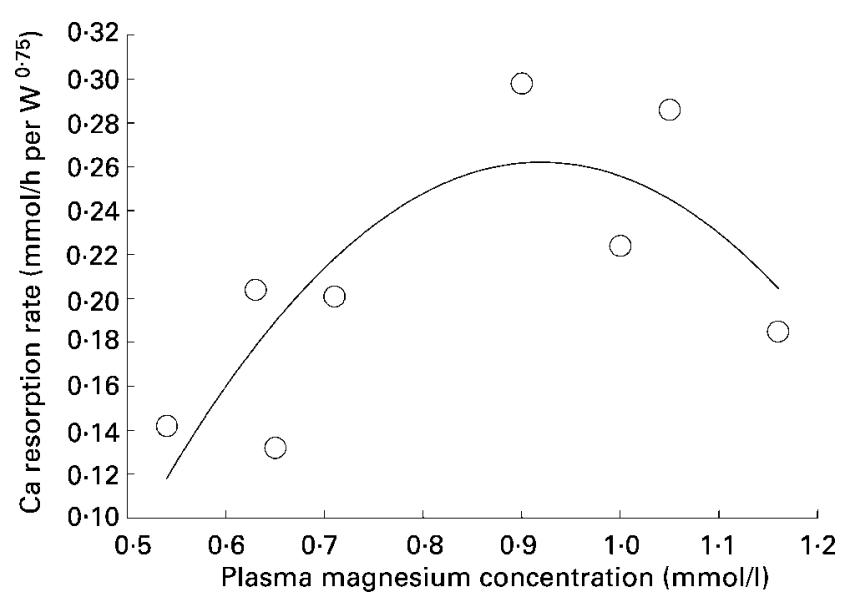

Fig. 4. Mean calcium resorption rate from bone corrected for metabolic live weight $\left(R^{\prime}, \mathrm{mmol} / \mathrm{h}\right.$ per $\mathrm{kg}$ live weight $\left.(\mathrm{W})^{0.75}\right)$, as a function of plasma magnesium concentration $(\mathrm{mmol} / \mathrm{l})$. $\mathrm{O}$, Data from Table $1 ;-$, fitted quadratic equation.

against the serum Mg levels, as shown in Fig. 4, a quadratic response is evident $(P<0 \cdot 1)$. This is interpreted to mean that when the serum levels of $\mathrm{Mg}$ are greater than the turning point (approx $0.91 \mathrm{mmol} / \mathrm{l}$ ), a reduction in serum $\mathrm{Mg}$ tends to increase the $\mathrm{Ca}$ mobilization from bone. Conversely, when the $\mathrm{Mg}$ serum levels are $<0.91 \mathrm{mmol} / \mathrm{l}$, there is a decrease in the rate at which $\mathrm{Ca}$ is mobilized from bone. These biphasic responses are consistent with the findings of Buckle et al. (1968) of reductions of parathyroid hormone in parathyroid venous plasma when the $\mathrm{Mg}$ concentration in the perfusion medium of the isolated gland was increased and the reverse trend when the $\mathrm{Mg}$ concentration in the perfusion fluid was reduced.

It thus appears that the mobilization of $\mathrm{Ca}$ from bone occurs only when the $\mathrm{Mg}$ levels are near normal and when the plasma $\mathrm{Mg}$ falls the potential for bone resorption is inhibited. Littledike et al. (1983) observed that the ability of the bone to supply $\mathrm{Ca}$ and $\mathrm{Mg}$ to the blood is progressively inhibited as the extracellular $\mathrm{Mg}$ concentrations decrease in $\mathrm{Mg}$ deficiency. Both Terashima et al. (1988) and Van de Braak et al. (1987b) noted a reduction in Ca mobilization from bone when the plasma $\mathrm{Mg}$ levels were lowered, while Littledike et al. (1983) observed that as hypomagnesaemia became severe, acute marked decreases in plasma hydroxyproline concentrations also occurred, a further indication that bone resorption was inhibited.

From this analysis, it is clear that in general bone acts as a small reservoir of $\mathrm{Mg}$. However, with a maximum Ca resorption rate of approximately $0.27 \mathrm{mmol} / \mathrm{h}$ per $\mathrm{kg}$ live weight ${ }^{0.75}$ (the maximum value in Fig. 4), a $500 \mathrm{~kg}$ animal could mobilize about $28.5 \mathrm{mmol} \mathrm{Ca}$ from bone/h. This value can be used to calculate the flux of $\mathrm{Mg}$ into the extracellular fluid in association with bone $\mathrm{Ca}$ turnover, on the assumption that $\mathrm{Ca}$ and $\mathrm{Mg}$ are resorbed non-preferentially. This assumption may require some caution in the light of the findings of Neuman \& Mulryan (1971) that in synthetic apetite crystals produced in vivo, $\mathrm{Mg}$ was located in readily exchangeable surface positions and may therefore be preferentially mobilized. On the other hand, there is overwhelming evidence from direct mineral analysis of the whole skeletons of sheep during changes of skeletal mineral content of up to $30 \%$ that the Ca:Mg ratio remains constant (Sykes \& Field, 1972; Sykes et al. 1974) or may even decrease in Ca deficiency (Field et al. 1975); this led Field et al. (1975) to speculate that $\mathrm{Mg}$ may substitute for $\mathrm{Ca}$ in skeletal mineral during Ca deficiency.

Assuming that $\mathrm{Ca}$ and $\mathrm{Mg}$ are resorbed from bone nonpreferentially, and with a 50:1 ratio of $\mathrm{Ca}: \mathrm{Mg}$, this means that a maximum of $0.57 \mathrm{mmol} \mathrm{Mg} / \mathrm{h}$ can be mobilized from the skeleton. This amounts to $0.33 \mathrm{~g} \mathrm{Mg} / \mathrm{d}$ for cattle, comparable with an independent estimate of $0.5 \mathrm{~g} / \mathrm{d}$ (Storry \& Rook, 1963). For a $25 \mathrm{~kg}$ sheep the comparable value is $0.035 \mathrm{~g} \mathrm{Mg} / \mathrm{d}$. These values are very small compared with either the daily endogenous losses of cattle or sheep ( 1.500 and $0.075 \mathrm{~g} \mathrm{Mg} / \mathrm{d}$ respectively) or to the normal daily urinary excretion of approximately 3.0 and $0.3 \mathrm{~g} \mathrm{Mg} / \mathrm{d}$ for animals on intakes of 10.0 and $1.5 \mathrm{~g} \mathrm{Mg} / \mathrm{d}$ respectively.

Consequently, the quantitative contribution to $\mathrm{Mg}$ dynamics from bone resorption is not considered to be an important component in our present model.

\section{Conclusions}

The extension of the model proposed here is able to account well for the dynamics of CSF $\mathrm{Mg}$ concentration observed in hypomagnesaemic ruminant animals. The possible quantitative contribution of bone turnover as a mechanism for $\mathrm{Mg}$ homeostasis has been discounted.

\section{Acknowledgement}

We are indebted to Flo Weingartner for his translation of Meyer \& Scholz (1972) into English.

\section{References}

Agricultural Research Council (1980) Nutrient Requirements of Ruminant Livestock. Farnham, Surrey: Commonwealth Agricultural Bureaux.

Allsop TF (1986) Transfer of magnesium across the perfused choroid plexus of sheep. Aust J Biol Sci 39, 161-169.

Allsop TF \& Pauli JV (1975a) Cerebrospinal fluid magnesium concentrations in hypomagnesaemic tetany. Proc NZ Soc Anim Prod 35, 170-174.

Allsop TF \& Pauli JV (1975b) Responses to the lowering of magnesium and calcium concentrations in the cerebrospinal fluid of unanaesthetized sheep. Aust J Biol Sci 28, 475-481.

Allsop TF \& Pauli JV (1985) Magnesium concentrations in the ventricular and lumbar cerebrospinal fluid of hypomagnesaemic cows. Res Vet Sci 38, 61-64.

Beal AM \& Bligh J (1977) Electrolyte concentrations in sheep cerebrospinal fluid. Res Vet Sci 22, 382-383.

Bito LZ (1969) Blood-brain barrier; evidence for active cation transport between blood and the extracellular fluid of brain. Science 165, 81-83.

Brody S (1945) Bioenergetics and Growth. New York: Reinhold Publishing Corporation.

Buckle RM, Care AD, Cooper CW \& Gitelman HJ (1968) The influence of plasma magnesium concentration on parathyroid hormone secretion. J Endocrinol 42, 529-534.

Charlton JA \& Armstrong DG (1989) The effect of an intravenous 
infusion of aldosterone upon magnesium metabolism in the sheep. $Q J$ Exp Physiol 74, 329-337.

Contreras PA, Manston R \& Sansom BF (1982) Calcium mobilisation in hypomagnesaemic cattle. Res Vet Sci 33, 10-16.

Cox PS (1977) Interrelationships of magnesium concentrations in the plasma and cerebrospinal fluid of the bovine. MSc Thesis, Iowa State University.

Cserr HF (1971) Physiology of the choroid plexus. Physiol Rev 51, 273-311.

Davson H (1967) Physiology of the Cerebrospinal Fluid. Boston, MA: Little, Brown.

Feldman BF (1989) Cerebrospinal fluid. In Clinical Biochemistry of Domestic Animals, 4th ed., pp. 835-865 [JJ Kaneko, editor]. San Diego, CA: Academic Press, Inc.

Field AC (1960) Uptake of magnesium-28 by the skeleton of the sheep. Nature 188, 1205.

Field AC, Suttle NF \& Nisbet DI (1975) Effects of diets low in calcium and phosphorus on the development of growing lambs. J Agric Sci Camb 85, 435-442.

Gardner JAA (1973) Control of serum magnesium levels in sheep. Res Vet Sci 15, 149-157.

Hemingway RG \& Ritchie NS (1965) The importance of hypocalcaemia in the development of hypomagnesaemic tetany. Proc Nutr Soc 24, 54-63.

Larvor P (1983) The pools of cellular nutrients: minerals. In Dynamic Biochemistry of Animal Production (World Animal Science; A3), pp. 281-317 [PM Riis, editor]. Amsterdam: Elsevier Science Publishers B.V.

Littledike ET, Stuedman JA, Wilkinson SR \& Horst RL (1983) Grass tetany syndrome. In Proceedings of the John Lee Pratt International Symposium on the Role of Magnesium in Animal Nutrition, pp. 173-195 [JP Fontenot, GE Bunce, KE Webb and VG Allen, editors]. Blacksburg, VA: Virginia Polytechnic Institute and State University.

Martens H (1983) Saturation kinetics of magnesium efflux across the rumen wall in heifers. Br J Nutr 49, 153-158.

Martens H \& Blume I (1986) Effect of intraruminal sodium and potassium concentrations and of the transmural potential difference on magnesium absorption from the temporarily isolated rumen of sheep. $Q J$ Exp Physiol 71, 409-415.

Martens H, Harmeyer J \& Michael H (1978) Magnesium transport by isolated rumen epithelium of sheep. Res Vet Sci 24, 161-168.

Meyer H \& Busse FW (1975a) Rectal absorption of magnesium in ruminants. Dtsch Tierarztl Wochenschr 82, 140-141.

Meyer H \& Busse FW (1975b) Effect of intravenous magnesium on the magnesium level in the cerebrospinal fluid of the sheep. Zentralbl Veterinarmed A22, 780-784.

Meyer H \& Scholz H (1972) Untersuchungen über die pathogenese der hypomagnesaemiachen tetanie 1. Beziehungen zwischen dem Mg-Gehalt im bult liquor cerebrophinalis beim schaf (Pathogenesis of hypomagnesaemic tetany I. Relationship between $\mathrm{Mg}$ content of blood and cerebrospinal fluid of sheep). Dtsch Tierarztl Wochenschr 79, 55-61.

Moate P, Boston RC \& Leaver D (1980) Calcium kinetics and absorption in normal and magnesium-deficient sheep. Anim Prod Aust 13, 448

Neuman WF \& Mulryan BJ (1971) Synthetic hydroxyapetite crystals IV. Magnesium incorporation. Calcif Tissue Res 7, $133-138$.
Oppelt WW, MacIntyre I \& Rall DP (1963) Magnesium exchange between blood and cerebrospinal fluid. Am J Physiol 205, 959-962.

Panaretto BA (1964) Body composition in vivo. VI. The composition of ewes during prolonged undernutrition. Aust J Agric Res 15, 771-787.

Parkinson GB \& Leaver DD (1980) The effect of experimental hyperkalaemia on cerebrospinal fluid magnesium. Anim Prod Aust 13, 447.

Pauli JV \& Allsop TF (1974) Plasma and cerebrospinal fluid magnesium, calcium and potassium concentrations in dairy cows with hypomagnesaemic tetany. NZ Vet J 22, 227-231.

Peters RH (1983) The Ecological Implications of Body Size. Cambridge: Cambridge University Press.

Robson AB, Field AC, Sykes AR \& McKinnon AE (1997) A model of magnesium metabolism in young sheep. Magnesium absorption and excretion. Br J Nutr 78, 975-992.

Rude RK, Oldham SB, Sharp CF \& Singer FR (1978) Parathyroid hormone secretion in magnesium deficiency. J Clin Endocrinol Metab 47, 800-806.

Shiga A, Kominato A \& Shinozaki K (1980) Experimental studies on hypomagnesaemia in ruminants V. Metabolism of phosphorus and plasma level of parathyroid hormone in sheep fed diets of varying composition of calcium and magnesium. Jpn J Vet Sci 42, 221-230.

Storry JE \& Rook JAF (1963) Magnesium metabolism in the dairy cow. V. Experimental observations with a purified diet low in magnesium. J Agric Sci Camb 61, 167-171.

Sykes AR \& Field AC (1972) Effects off dietary deficiencies of energy, protein and calcium on the pregnant ewe. 1. Body composition and mineral content of ewes. J Agric Sci Camb 78, 109-117.

Sykes AR, Field AC \& Gunn RG (1974) Effects of age and incisor dentition on the chemical composition of the skeleton of sheep grazing hill pastures. J Agric Sci Camb 83, $145-150$.

Sykes AR \& Russel AJF (2000) Deficiency of mineral macroelements. In Diseases of Sheep, pp. 318-331 [WB Martin and ID Aitken, editors]. Oxford: Blackwell Science.

Terashima Y, Matsunobu S, Yanagisawa T \& Itoh H (1988) Calcium mobilization in hypomagnesaemic wethers fed on a low magnesium and or a high potassium diet. Jpn J Zootech Sci 59, $75-81$.

Van de Braak AE, van't Klooster ATh, Goedegebuure SA \& Faber JAJ (1987a) Effects of calcium and magnesium intakes and feeding level during the dry period on bone resorption in dairy cows at parturition. Res Vet Sci 43, 7-12.

Van de Braak AE, van't Klooster ATh \& Malestein A (1986a) Influence of prepartum calcium intake on calcium mobilization rate around parturition in dairy cows fed at a high prepartum feeding level. Vet $Q \mathbf{8}, 24-37$.

Van de Braak AE, van't Klooster ATh \& Malestein A (1987b) Influence of a deficient supply of magnesium during the dry period on the rate of calcium mobilisation by dairy cows at parturition. Res Vet Sci 42, 101-108.

Van de Braak AE, van't Klooster ATh, Malestein A \& Faber JAJ (1986b) Effects of low and high calcium intake prepartum on calcium mobilization rate around parturition in dairy cows. Vet $Q \mathbf{8}, 12-23$. 